Philosophy \& Phenomenological Research 92 (2016): 492-508

(please cite published version)

\title{
Expert Opinion and Second-Hand Knowledge
}

\author{
Matthew A. Benton \\ University of Oxford
}

Recent work on testimony and the norms of assertion considers cases of expert testimony. Thinking about expert testimony clarifies which epistemic goods figure in the expectations placed on experts for their knowledge. Examining the distinctive conditions of expert testimony and the assumptions hearers bring to such conversational contexts can provide broader lessons about how knowledge is represented by speakers, and how it is gained by hearers.

Expert testimony is the focus of Jennifer Lackey's $(2011,2013)$ recent arguments over the norm of assertion. Her cases suggest that experts are plausibly held to a different epistemic standard when speaking as experts, where this standard concerns not only the quantity of an expert's epistemic support for what an expert asserts, but also the quality of that epistemic support. These cases seem to count against knowledge being sufficient for epistemically permissible assertion; and several others have followed Lackey in regarding such cases as important to adjudicating the debate over the norms of assertion and practical reasoning (Carter and Gordon 2011, Coffman 2011, McKinnon 2012, Carter 2014, Gerken 2014, Green forthcoming).

I shall argue in this paper that relying on intuitions about such cases of expert testimony introduces several problems concerning expertise, expert knowledge, and the sharing of such knowledge through testimony. 
In particular, the cases used thus far are unstable, and refinements are needed to clarify exactly what principles are being tested and exactly what our intuitive judgements are tracking in such cases. But as we shall see, once refined, such cases raise more questions than they answer.

The plan of this paper is as follows. $§ 1$ introduces the sufficiency principle for epistemically permissible assertion, and notes how it does and does not relate to the knowledge norm of assertion. \$2 considers Lackey's notion of isolated second-hand knowledge, clarifying various notions of knowledge as 'isolated' and of seeking an expert's opinion. \$3 exposes a significant problem with relying on intuitions about cases of experts as-

serting with isolated second-hand knowledge. Section $\S_{4}$ evaluates some potential replies.

\section{Principles of Permissible Assertion}

In the recent literature, norms of assertion are typically cast as a necessary condition on epistemically permissible assertion: an assertion, to be epistemically acceptable, must at least meet the condition stated by the norm, though the assertion might still be improper on other grounds (for example if it is impolite, or irrelevant, etc.). Thus Timothy Williamson's knowledge rule of assertion states that

(KN) One must: assert $p$ only if one knows that $p \cdot(2000,243)$

Competitors to the knowledge rule typically endorse this necessary condition schema, while substituting in their favoured status or state, for example the Truth rule (Weiner 2005), the Rational Credibility rule (Douven 2006), the Reasonable-to-Believe norm (Lackey 2007/2008, Ch. 4), the Supportive Reasons norm (McKinnon 2013), among others.

$\mathrm{KN}$ offers only a necessary condition on epistemically permissible assertion; most defenders of $\mathrm{KN}$ refrain from endorsing a comparable sufficiency condition on assertion, which would make knowing sufficient 
for epistemically permissible assertion. ${ }^{1}$ One reason why fans of $\mathrm{KN}$ do not do so is because $\mathrm{KN}$ seems implausibly strong as a sufficiency condition:

(KN-S) One must: assert $p$ if one knows that $p$.

On the KN-S rule, one must assert whatever one knows! A more plausible sufficiency principle is the following, labelled KNA-S* by Lackey:

$\left(\mathrm{KNA}^{*}{ }^{*}\right)$ One is properly epistemically positioned to assert that $p$ if one knows that $p .^{2}$

Some are tempted to think that those committed to $\mathrm{KN}$ are likewise committed to some sufficiency principle like KNA-S* (see e.g. Hawthorne 2004,23 n. 58). One idea behind the temptation goes roughly like this: if knowledge that $p$ is required for epistemically permissible assertion that $p$ (as per $\mathrm{KN}$ ), then knowing $p$ is what positions one, epistemically speaking, for properly asserting that $p$; thus KNA-S* follows from KN. But this argument is flawed. $\mathrm{KN}$ might be true though KNA-S* false: if one can know that $p$, and thereby meet $\mathrm{KN}$, but be in a conversational context where something 'stronger' than knowledge is also required for permissible assertion (say, certainty, if certainty can come apart from knowledge), then in that context one would not be properly epistemically positioned to assert that $p$ even while knowing $p$, and $\mathrm{KNA}^{*}{ }^{*}$ would be false. Similarly, one might know $p$ but be in a conversational context in which one must know $p$ on particular grounds in order to assert $p$ flat-out in that context. (Indeed, Lackey's cases discussed below will trade on just such a

\footnotetext{
${ }^{1}$ Thus Williamson, Hawthorne (2004, 23-24), Turri (2010, 2011, 2014), Benton (2011, 2012, forthcoming), Sosa $(2011,45-52)$, and Blaauw (2012), among others, all defend only (or primarily) the necessary condition. For discussion of a sufficiency condition, see Brown 2010 and 2011, and Lackey as discussed below.

${ }^{2}$ See Lackey $(2011,252)$; such a principle, or something much like it, is endorsed by Keith DeRose (2009, 93).
} 
scenario.) Because it seems that there can be cases where something over and above knowing is required, epistemically, for proper assertion, ${ }^{3} \mathrm{KN}$ might be true though $\mathrm{KNA}^{*}{ }^{*}$ is false. Thus defenders of KN arguably need not be committed to KNA-S*. Even still, some supporters of KN have accepted, or been inclined to accept, KNA- $S^{*} .{ }^{4}$ As a result, some critics have endeavoured to argue against a sufficiency principle like KNA-S* on epistemically permissible assertion. It is to those arguments that we now turn.

\section{Isolated Second-Hand Knowledge}

Lackey introduces cases of what she calls isolated second-hand knowledge (ISHK) to argue specifically against KNA-S*, because they are cases designed to be ones where intuitively, the asserter knows, and yet intuitively the assertion is still (epistemically) improper. Assertions of some proposition $p$ based on ISHK are those where a speaker knows $p$ only through another's testimony (the knowledge is entirely second-hand), and the speaker 'knows nothing (or very little) relevant about the matter other than that $p^{\prime}$ (thus it is isolated) $(2011,254)$. Getting a feel for these notions is best done by considering Lackey's cases; though she gives several versions of such cases (EXPERT PANELIST and PROFESSOR: 2011, 253-54; cf. also Food and MOvie, p. 257, and RECOMMENDATION and CHEATING, pp. 259-26o), they are structurally similar with respect to the issues of interest here, and so any points made in this paper may be made for those cases as well. Because space considerations prevent us from discussing

3Plausibly, one who endorses Williamson's view of KN as the unique epistemic norm governing assertion will thereby be committed to something like KNA-S*, because on this view, having fulfilled KN means having fulfilled the only epistemic norm, and thus there cannot be any other epistemic norm-like requirements on speakers (thanks to Lizzie Fricker here). But defenders of KN needn't adopt this uniqueness claim; see e.g. Turri $\left(2014, \S_{1}\right)$ for recent discussion.

${ }^{4}$ For other reasons for accepting a sufficiency direction of the knowledge norm, see Hawthorne $(2004,87$ ), as well as Fantl \& McGrath's (2009, 66ff.) arguments for (KJ). Because my concern in this paper is with a specific style of counterargument against KNA-S* I do not here further consider what might be said in its favor. 
each case, we shall concentrate on her doctor cases:

DOCтоR: Matilda is an oncologist at a teaching hospital who has been diagnosing and treating various kinds of cancers for the past fifteen years. One of her patients, Derek, was recently referred to her office because he has been experiencing intense abdominal pain for a couple of weeks. Matilda requested an ultrasound and MRI, but the results of the tests arrived on her day off; consequently, all the relevant data were reviewed by Nancy, a competent medical student in oncology training at her hospital. Being able to confer for only a very brief period of time prior to Derek's appointment today, Nancy communicated to Matilda simply that her diagnosis is pancreatic cancer, without offering any of the details of the test results or the reasons underlying her conclusion. Shortly thereafter, Matilda had her appointment with Derek, where she truly asserts to him purely on the basis of Nancy's reliable testimony, 'I am very sorry to tell you this, but you have pancreatic cancer.' $(2011,253)$

Lackey thinks that intuitively, Matilda's assertion is improper; but we shall consider that at length in the next section $\left(\S_{3}\right)$. Clearly, Matilda's knowledge that Derek has pancreatic cancer is entirely second-hand (since she learned this solely through Nancy's testimony). And it is isolated in Lackey's sense because Matilda did not hear from Nancy any of the other details of the test results that indicate cancer. Had Matilda discussed these details with Nancy, then Matilda's knowledge would not be isolated because she would know more about what evidence supports the diagnosis, and would thereby have 'second-hand expertise' (2011, 256); or, had Matilda herself seen the test results and assessed them for herself, her knowledge would instead be (at least partly) first-hand.

Some however lack the intuition that Matilda knows in Dоctor, because Nancy, being only a medical student, is not a peer nor an expert 
of Matilda's level. 5 Perhaps sensing this, in Lackey 2013 the oncologist case is changed from Nancy being 'a competent medical student training at her hospital,' to being 'a very competent colleague in oncology' (italics added); I shall charitably interpret this as Nancy being a fellow doctor and oncologist at the hospital. To get things more clear then, the case to be used will be modified to DOctor1 so that Nancy is not a student but a fellow oncologist:

DостоR1: Matilda is an oncologist at a teaching hospital who has been diagnosing and treating various kinds of cancers for the past fifteen years. One of her patients, Derek, was recently referred to her office because he has been experiencing intense abdominal pain for a couple of weeks. Matilda requested an ultrasound and MRI, but the results of the tests arrived on her day off; consequently, all the relevant data were reviewed by Nancy, a very competent colleague in oncology. Being able to confer for only a very brief period of time prior to Derek's appointment today, Nancy communicated to Matilda simply that her diagnosis is pancreatic cancer, without offering any of the details of the test results or the reasons underlying her conclusion. Shortly thereafter, Matilda had her appointment with Derek, where she truly asserts to him purely on the basis of Nancy's reliable testimony, 'I am very sorry to tell you this, but you have pancreatic cancer.' (2013, 34-35)

Though the idea of knowing a proposition entirely second-hand seems clear enough, one might wonder exactly what it is for one's knowledge to be isolated in the relevant sense. Considering cases of multiple testimonial sources may seem to make one's knowledge isolated, yet it provides

5That is, one might be assuming a principle such that: testimony consisting simply of an assertion that $p$ from a non-expert to an expert on a matter of the expert's expertise does not confer knowledge (at least if the testimony is the only reason for the expert to believe $p$ ). 
more knowledge about the matter than simply that $p$. For example, had Matilda received not only the testimony from Nancy as in DостоR 1 but also similar testimony from three other competent oncologists (Drs. X, $\mathrm{Y}$, and $\mathrm{Z}$ ) who also reviewed the test results independently and testified to Matilda solely that their own diagnosis is cancer, without discussing any more details, would Matilda's knowledge still be isolated ${ }^{6}$ After all, Matilda now knows not only that Nancy concluded that $p$, but also that Dr. $\mathrm{X}$ concluded that $p$, and that Dr. Y concluded that $p$, and that Dr. Z concluded that $p$. Moreover, Matilda also knows that Dr. Y and Dr. $Z$ agree in their diagnoses, that Nancy and Dr. $X$ agree in their diagnoses, that each oncologist reached their conclusions independently, and so on. This is a lot of additional knowledge compared with the DOcTOR1 case; would this added knowledge make Matilda's knowledge that $p$ non-isolated?

Additionally, one might wonder how much turns on the notion of seeking an expert opinion. Let us suppose that giving one's own expert opinion typically (perhaps constitutively) requires that the expert have either firsthand acquaintance with some relevant data in the domain of expertise from which one employs one's expertise in drawing a conclusion, or for it to be thorough knowledge of all the relevant details if it is all secondhand. 7 The Doctor cases are written as if Derek was referred to Matilda's office to get an expert oncologist's opinion, but how we understand that idea will matter to our judgments about these cases. On one interpretation, Derek may be seeking an expert's opinion such that he simply wants any oncologist with the relevant expertise to evaluate his symptoms: call this approach Any-Expert. On this assumption, Matilda could give an expert opinion without giving her own expert opinion. Yet on another interpretation, Derek specifically wants Matilda's own expert opinion: call this Specific-Expert. It is worth flagging that if we read DостоR1 with Any-Expert as the background assumption, we are less likely to have the intuition that Matilda's assertion is improper than if we are assuming Specific-Expert. (Note also that even when assuming the weaker Any-

\footnotetext{
${ }^{6} \mathrm{~A}$ similar issue is raised by McGrath (2010, $401 \mathrm{n} .17$ ).

${ }^{7}$ Cf. Lackey 2011, 270: 'we do not expect expert testimony to be grounded purely in isolated second-hand knowledge.'
} 
Expert, one might judge Matilda's assertion in the original Doctor case, in which Nancy is a medical student but not a full doctor, to be improper for Gricean reasons: Derek seeks a doctor's opinion, but is in fact getting a medical student's opinion, and so Matilda's assertion is at least pragmatically misleading. ${ }^{8}$ )

Thus there are at least two dimensions on which one's intuitions of the DOctor case can depend: these dimensions can affect how one assesses Matilda's assertion for propriety, even if one intuitively thinks Matilda knows. One can interpret Nancy's role in the original case as (i) a less-qualified medical student, or as (ii) a fellow expert and colleague as in DостоR 1; and one can interpret Derek's expectations to be captured by either (iii) Any-Expert or (iv) Specific-Expert. The combinations of these possibilities are captured by the following diagram:

\begin{tabular}{lll} 
& \multicolumn{1}{c}{ Any-Expert } & \multicolumn{1}{c}{ Specific-Expert } \\
\hline $\begin{array}{l}\text { Nancy: med stu- } \\
\text { dent (DOCTOR) }\end{array}$ & $\begin{array}{l}\text { pragmatically misleading: } \\
\text { Derek seeks a doctor's } \\
\text { opinion }\end{array}$ & $\begin{array}{l}\text { pragmatically misleading: } \\
\text { Derek seeks Matilda's } \\
\text { opinion }\end{array}$ \\
\hline $\begin{array}{l}\text { Nancy: oncologist } \\
\text { (DOCTOR1) }\end{array}$ & pragmatically acceptable & $\begin{array}{l}\text { pragmatically misleading: } \\
\text { Derek seeks Matilda's } \\
\text { opinion }\end{array}$ \\
\hline
\end{tabular}

Notice that one's intuitions about epistemic propriety might be affected by the same issues, particularly if one regards the epistemic propriety of asserting as an expert to be connected to how an expert represents herself and her expertise in conversation: if speaking as an expert will be misleading when one appears to offer one's own expert opinion even though one did not engage one's expertise in arriving at that opinion, then such asser-

\footnotetext{
${ }^{8}$ Thanks to Dani Rabinowitz for pointing this out.
} 
tions may also seem epistemically improper. ${ }^{9}$ Thus one's background assumptions, particularly given the Any-Expert/Specific-Expert distinction, seem to matter greatly to one's intuitions about these cases.

\section{Assessing for Impropriety}

Lackey contends that DOCTOR and DOCTOR1 reveal assertions based on ISHK to be epistemically improper: that Matilda's knowledge is both isolated and second-hand 'makes it improper for her to flat-out assert this diagnosis to Derek' $(2011,255)$. This is because Lackey maintains that DocTOR1 is a context in which Derek 'reasonably has the right to expect the asserter to possess more than merely isolated second-hand knowledge'; if this expectation is not met, Derek has the right to resent Matilda's assertion (2011, 254-55; thus Lackey seems to be assuming Specific-Expert). Lackey says this impropriety is not a merely a pragmatic one of misleading Derek with respect to this expectation; rather, 'in my cases, ... the remaining impropriety involves the asserter's epistemic relation to that which she asserted' $(2011,265)$, for Matilda 'lacked the epistemic authority to flatout assert this diagnosis to Derek in any way at all' $(2011,264)$. If all this is correct, then DOCTOR1 and her other ISHK cases are counterexamples to KNA-S*.

Before raising some difficulties for Lackey's view of DOctoR1, it is worth noting the tension that view creates given her earlier cases of 'selfless assertions' (2007/2008, Ch. 4). Selfless assertion cases are those in which a subject asserts $p$ because $p$ is well-supported by all of the

${ }^{9}$ For example, one might be implicitly assuming from the outset that expert testimony is constituted by the following principle:

(E) Whenever an expert of domain $D$, speaking as an expert, gives a statement that is either (i) not based on first-hand assessment of data relating to $D$ but instead offers the view of a fellow expert, or (ii) is modified to align with political/social/institutional policies, the expert's statement does not qualify as an expert opinion.

Given (E), and assuming Specific-Expert, Matilda in DOcTOR1 would be speaking improperly in some sense, for it seems she is representing herself as giving her expert opinion even though (E) states that what she is offering is not an expert opinion; but it is not clear whether this is an epistemic or pragmatic (or some other) violation. Thanks to Dani Rabinowitz for discussion here. 
available evidence, yet the subject, for non-epistemic reasons, does not believe $p$ and so does not know $p$ (2008, 110-113). She uses another doctor case to illustrate:

DistraUght DOctor: Sebastian is an extremely well-known paediatrician and researcher who has done extensive work studying childhood vaccines. He recognises and appreciates that all of the scientific evidence shows that there is absolutely no connection between vaccines and autism. However, shortly after his apparently normal 18 -month-old daughter received one of her vaccines, her behaviour became increasingly withdrawn and she was soon diagnosed with autism. While Sebastian is aware that signs of autism typically emerge around this age, regardless of whether a child received any vaccines, the grief and exhaustion brought on by his daughter's recent diagnosis cause him to abandon his previously deeplyheld beliefs regarding vaccines. Today, while performing a well-baby check-up on one of his patients, the child's parents ask him about the legitimacy of the rumours surrounding vaccines and autism. Recognizing both that the current doubt he has towards vaccines was probably brought about through the emotional trauma of dealing with his daughter's condition and that he has an obligation to his patients to present what is most likely to be true, Sebastian asserts, 'There is no connection between vaccines and autism.' In spite of this, at the time of his assertion, it would not be correct to say that Sebastian himself believes or knows this proposition. $(2008,110-11)$

Lackey maintains that the evidence had by the subjects in her selfless assertion cases provide them 'enough epistemic support' that 'they would know [the supported propositions] were they to believe them' $(2008,114$ n. 19). Because Lackey judges such selfless assertions to be praiseworthy rather than inappropriate, she regards Sebastian to be asserting entirely properly in DISTRAUGHT DOCTOR; yet as we saw above, Lackey also judges Matilda to be speaking (epistemically) improperly in DостоR1. Thus Lackey seems committed to the idea that when one is speaking as 
an expert, possessing first-hand access to probative evidence for $p$, even if one doesn't believe $p$ on that evidence, is more important to the propriety of one's assertion that $p$ than having isolated second-hand knowledge that $p$. That is, by Lackey's lights it would be better (so far as the permissibility of assertion goes) for an expert to have first-hand evidence, regardless of whether she believes what that evidence supports, than to believe or even know on the testimony of a fellow expert. ${ }^{10}$

This difficulty in Lackey's own view notwithstanding, we can still evaluate DOCTOR1 for its applicability to a sufficiency principle like $\mathrm{KNA}^{*}$. If one shares the intuition that Matilda's assertion is improper due to her inadequate epistemic relation to what she asserts, then KNA-S* will seem false. But by varying the DOCTOR1 case only slightly, it becomes clear that the impropriety infecting Matilda's assertion has nothing to do with her epistemic relation to it. Consider the following case:

DOCTOR2: Matilda is an oncologist at a teaching hospital who has been diagnosing and treating various kinds of cancers for the past fifteen years. One of her patients, Derek, was recently referred to her office because he has been experiencing intense abdominal pain for a couple of weeks. Matilda requested an ultrasound and MRI, but the results of the tests arrived on her day off; consequently, all the relevant data were reviewed by Nancy, a very competent colleague in oncology at her hospital. Being able to confer for only a very brief period of time prior to Derek's appointment today, Nancy communicated to Matilda simply that her diagnosis is pancreatic cancer, without offering any of the details of the test results or the reasons underlying her conclusion. Shortly thereafter, Matilda had her appointment with Derek with Nancy in attendance, where Matilda truly asserts to Derek purely on the basis of Nancy's reliable testimony, 'I am very sorry to tell you this, but you have pancreatic cancer.'

\footnotetext{
${ }^{10}$ Notice furthermore that if one assumes Specific-Expert in evaluating DISTRAUGHT DостоR, one will likely regard Sebastian's assertion to be at least pragmatically misleading and improper in that sense. This suggests that Lackey needs her readers to assume Any-Expert in her selfless assertion cases (so that there is no intuition of epistemic impropriety), but Specific-Expert in her ISHK cases (so that we have an intuition of impropriety).
} 
In DOcToR2, Matilda's epistemic relation to what she asserts remains exactly as it was in DOCTOR1. But in DOCTOR2, with Nancy in the room with Matilda and Derek when Matilda asserts to him that he has pancreatic cancer, the intuition that Matilda's assertion is epistemically improper vanishes: there seems to be nothing epistemically objectionable about Matilda's assertion. With Nancy on hand to field Derek's questions from first-hand knowledge, Derek would not be entitled to resent Matilda's asserting based on ISHK in that context. ${ }^{11}$ If so, then it cannot be that the impropriety present in DOCTOR 1 is due to Matilda's epistemic relation to what she asserts; for that epistemic relation is exactly the same in DocTOR2, where Matilda's assertion is intuitively proper (or at least, it is not intuitively improper). (Similar results follow from similar slight changes to Lackey's other cases EXPERT PANELIST and PROFESSOR (2011, 253-254), as well as to revisions of her 'presumed-witness' cases, e.g. CHEATING (2011, 260). Lackey also discusses cases of 'judgments' by non-experts (FOOD and MOVIE: 2011, 257-58), but I lack the intuition that the asserters in these cases know.)

The differences between DOCTOR1 and DOCTOR2 help us to see the flaw in Lackey's assessment of her original ISHK cases. First, Lackey's insistence that Derek reasonably has the right to expect the asserter to possess more than merely isolated second-hand knowledge depended on her assumption of Specific-Expert. But the intuitive response to DOCTOR2 reveals that in fact, some weaker assumption (perhaps Any-Expert) is more apt: in particular, Derek at most has the right to expect that someone in the conversation possess more than isolated second-hand knowledge, from whom he can gain an understanding of the test results and how they support the diagnosis. ${ }^{12}$ Second, from the idea that Derek reasonably has a right to

\footnotetext{
${ }^{11}$ It is interesting to consider how 'downstream' norms of assertion that require one to defend or retract one's assertion (e.g. Rescorla 2009 and Macfarlane 2011) would handle cases such as DOCTOR1 and DOCTOR2: for those norms require the speaker herself to defend the assertion. To the extent that one shares the intuition that Matilda's assertion is epistemically innocuous in DOCTOR2, this puts pressure on the exact duty imposed by such 'defend or retract' norms; e.g., such norms do not fit well with the assumption of Any-Expert.

${ }^{12}$ Some may balk even at this, and contend instead that Derek has no such right; or that if he does have some kind of patient's right to such information, that this fact places no particularly epistemic requirement on Matilda not to assert the initial diagnosis. Rather,
} 
expect that the asserter have more than ISHK, Lackey infers that Matilda, who did not have more than ISHK, lacked the epistemic authority to flatout assert that diagnosis to Derek, and contends that this fact is what explains the intuition of impropriety in DOCTOR1. But as shown by contrasting DOCTOR1 with DOCTOR2, that intuition can be explained merely by the absence of someone in the conversation who possesses the first-hand knowledge and can explain the results to Derek. (One might suppose that the person in the conversation who possesses the first-hand knowledge must also be the person from whom the asserter gained her ISHK. Though that sounds initially plausible, it may not be correct, for one can imagine a new doctor case, DOctor3: Nancy has told Matilda the diagnosis (and nothing more), but Nancy cannot make the appointment with Derek, and so Nancy sends her oncologist colleague Rachel-who also reviewed the lab results and so has first-hand knowledge-to be at the appointment with Matilda and Derek. My own intuition of such a case remains just as in DOCTOR2.)

\section{$4 \quad$ Strategies for Reply?}

Someone convinced by Lackey's ISHK cases might plausibly respond to this challenge in one of two ways. One approach denies that considering the DOCTOR2 case reveals anything about Matilda's epistemic relation to what she asserts in Lackey's original DOcTOR1 case. Another approach concedes that the DOcтоR2 case reveals something important about Matilda's epistemic relation to what she asserts in the original DOCTOR1, but maintains nevertheless that her epistemic relation is still wanting. ${ }^{13}$ I shall discuss these in turn.

any such responsibility is generated by healthcare policy that she provide that information. For the sake of argument I shall assume, however, that the relevant requirement is epistemic and not grounded in any such institutional norms.

${ }^{13} \mathrm{~A}$ third reply holds fast to Specific-Expert and just insists that Matilda in DостоR2 still asserts (epistemically) impermissibly, thereby denying the intuition. To those inclined to make this move, I urge them to consider their intuitions of comparative propriety: doesn't Matilda's assertion in DOcтоR2 seem much more appropriate than her assertion in DOctoR1? Why would this be, if they are both epistemically impermissible in the sense articulated by Lackey? 


\subsection{Defense 1}

The first approach insists that even if Matilda in DOcTOR2 asserts epistemically permissibly, this does not show that Matilda in DOCTOR1 also asserts epistemically permissibly. This approach looks initially unpromising, for it has the burden of explaining why it would be that Matilda's assertion in DOCTOR2, but not in DOCTOR1, is epistemically permissible, given that Matilda's epistemic relation to what she asserts remains exactly the same in each case. I can envision two ways in which one might discharge this burden: one appeals to a defeater, the other appeals to group assertion. I'll briefly argue that neither route offers an adequate defense.

One attempt to discharge the burden of explaining the difference in epistemic permissibility between DOCTOR1 and DOCTOR 2 might be by appealing to some kind of defeater: perhaps the ISHK cases, such as Lackey's DOCTOR1, can be subject to a kind of overriding defeater which kicks in when a person who possesses more than merely ISHK is alongside the asserter in the conversational context while she asserts. In DOCTOR2 this has the effect of defeating the epistemic impermissibility of the assertion based solely on ISHK; but in the absence of this defeater, the cases of assertions based entirely on ISHK are impermissible, and the existence of these cases is sufficient to undermine KNA- ${ }^{*}$.

This first envisioned reply does not succeed. Constructing an account of such defeaters might suffice to show how Matilda's assertion in DOctor2 is epistemically permissible even if her assertion in DOCTOR1 is not; but it does so at the cost of making the epistemic permissibility of assertion depend on something other than the speaker's epistemic relation to what is asserted. And once one agrees that the epistemic relation of the speaker to what is asserted is not what makes for an assertion's epistemic permissibility, one jettisons the crucial premise of Lackey's project, namely, that cases of ISHK undermine KNA-S* because they are cases where the asserter's epistemic relation to what is asserted ought (given KNA-S*) to make the assertion epistemically permissible.

Another way to explain the difference in epistemic permissibility between the assertions in DOCTOR1 and DOCTOR2 appeals to the idea that in DOCTOR2, with her colleague present in the room, Matilda is plausibly understood as speaking for them both. On this idea, the two doctors together assert to Derek that he has cancer, even if only one of them does the talking. In DостоR2, if the assertion is coming from both the oncol- 
ogists, it is not an assertion of second-hand knowledge, and this would explain why intuitively, the assertion is epistemically permissible in DocTOR2 while the relevant assertion in DOCTOR1 is intuitively not epistemically permissible. ${ }^{14}$

There are interesting and subtle issues raised by this example, such as (i) whether a member of a group (in this case, a group of two) can have, and express through assertion, first-hand knowledge simply by being part of a testimonial chain that includes someone who has first-hand knowledge, and (ii) whether speaking as a group enables an expert member of the group to fulfil a background principle of evaluation like Specific-Expert (and these issues are beyond the scope of the present paper). But taken simply as an explanation of the difference in epistemic permissibility between the assertions in DOCTOR 1 and DOCTOR2, this move is highly problematic. For if this move is plausible in the case of DOCTOR2, there does not seem to be any principled reason why it is unavailable to appeal to in the case of DOCTOR1: for it does not seem that Matilda's colleague must to be in the room in order for Matilda to be speaking for them both. Indeed, if we imagine that in DOCTOR1, Matilda's assertion is prefaced by 'I've spoken with my colleague about your lab results, and we're sorry to have tell you that you have pancreatic cancer', it will seem as though Matilda is speaking for both herself and her (absent) colleague. So, far from this move being able to explain the difference in epistemic assertability, it actually provides a recipe for explaining away the original intuition of epistemic impropriety in DOCTOR1.

\subsection{Defense 2}

So much for the first line of defense. A second response to our challenge proceeds by claiming that Matilda lacks the requisite epistemic authority to assert in DOCTOR1 because her epistemic relation to the asserted diagnosis is more subtle than had been previously appreciated, and this is a subtlety brought out by considering DостоR2: in order to assert the

\footnotetext{
${ }^{14}$ Thanks to Lizzie Fricker for raising such a case. One might think that this move is supported by considering a further modified case: if we imagine that the colleague is in the room with Matilda but is hidden, the impropriety intuition about Matilda's assertion remains (at least for some). However, as I discuss in the next paragraph, this intuition is also unstable, for it is unclear that the location of the colleague needs to matter to whether Matilda may speak for the group.
} 
diagnosis to Derek, Matilda's epistemic relation must include knowing (or having good reason to believe) that someone can explain to Derek why that diagnosis is the right one given the lab results. More generally,

Expert Norm: it is an expert's responsibility, qua (expert) asserter, to assert $q$ (flat-out) to a hearer only if the expert knows that $q$ and knows, or has good reason to believe, that someone (with more than ISHK) can explain why $q$ to the hearer in that context.

Thus having adequate epistemic authority to assert, qua expert, in these special contexts requires a strong epistemic relation (though a slightly indirect relation) to the proposition asserted; and in these contexts, this is a relation requiring more than simply ISHK. ${ }^{15}$ (As Lackey puts it, one must have the right 'quality, ${ }^{16}$ and not just quantity, of epistemic support: 2011 271.) It is precisely because experts typically satisfy the epistemic requirements of both asserter and explainer that Lackey's cases attract interest: such cases exploit scenarios wherein the expert seems (given KNA$\mathrm{S}^{*}$ ) to have just enough epistemic backing to assert, but not enough (or the right quality) to explain.

This response looks more promising, for it is able to capture the different intuitions about each of the above doctor cases, while preserving Lackey's aim of showing assertions based merely on ISHK to be problematic in certain expert cases. But this solution has two drawbacks. First, the kind of epistemic relation required by EXPERT NORM in fact invokes two epistemic relations, namely one to the asserted proposition, and one to the proposition that someone in the conversation can explain or support the proposition asserted. In so doing, it does not rule out an expert

\footnotetext{
${ }^{15}$ Thanks to John Turri for raising this idea.

${ }^{16}$ It is unclear, however, what Lackey means by 'quality'. It might be defined in terms of some knowledge being either non-isolated or (partly) first-hand (indeed, Lackey seems to talk about it in this way in $2011,271 \mathrm{ff}$.). Or it might be defined in terms of one's source of knowledge, be it by way of testimony, the senses, or reasoning, etc.: if so, then it seems to track merely the first- vs. second-hand distinction. But questions still loom about the quantity/quality distinction: e.g. does someone who has one sound deductive argument for $p$ have a higher quality, but lower quantity, of epistemic support for $p$ than another person who has four inductive (and no deductive) arguments for $p$ ? For these reasons, I have largely avoided the terminology of quality/quantity in this paper.
} 
asserting $p$ with only ISHK of $p$, so long as the expert also knows or has good reason to believe that someone else in the conversation can explain why $p$. Thus ExPERT Norm is of no help to Lackey's avowed aim to show that the impropriety of such assertions stems from the asserter's epistemic relation to the asserted proposition: for EXPERT NORM does not deliver the results that an expert's assertion of $p$ is flawed because he or she lacks some epistemic authority or epistemic position with respect to $p$.

The second drawback is this: arguably ExPERT Norm's second epistemic relation is too demanding. For in DостоR 1 Matilda could assert to Derek in violation of the responsibility set out by EXPERT Norm, yet add qualifications that explain why she does so. For example, given only her ISHK, Matilda could plausibly assert to Derek (without having any colleagues present) and add: 'I have not had time to review all the test results to my satisfaction yet, so I'm not currently in a position to provide all the details that you might like, beyond the unfortunate diagnosis that I'm sorry to have to give you, and which is not in doubt. We should definitely make another appointment for you soon so that we can review it together and answer all your questions. ${ }^{17}$ Derek might well be disappointed with this; but it seems implausible that he could reasonably resent Matilda's assertion for being epistemically inadequate.

Lackey considers such an addition to Matilda's assertion (2011, 265; cf. also 255): for example, Matilda could add to her assertion, 'but I myself have not seen any of your tests results, nor do I have any specific reasons to offer to defend this diagnosis'. ${ }^{18}$ Yet Lackey thinks adding this would not

eliminate the wrongness or epistemic impropriety of [Matilda's initial assertion]. Derek would still rightly feel resentful, even incensed, that his oncologist had flat-out asserted a cancer diagnosis to him without being able to offer any direct support on its behalf. $(2011,265)$

\footnotetext{
${ }^{17}$ Thanks to John Turri here.

${ }^{18}$ The second clause ('nor do I have...') seems conspicuously designed to elicit an intuition of impropriety, since it invokes having to defend the diagnosis. But worse, that clause seems false, or at least misleading, given that Matilda does have a specific reason for the diagnosis: her trustworthy expert colleague, who had first-hand access to the test results, testified to it.
} 
I confess that I don't find this plausible at all. Any residual resentment Derek might have is most plausibly moral or professional ${ }^{19}$ in nature: perhaps one's doctor should only deliver news of a cancer diagnosis in a context where the patient can learn more about the diagnosis, precisely because it is the compassionate thing to do, because it engenders trust in one's doctors, and so on. But these would be moral or professional or prudential norms, not epistemic ones. ${ }^{20}$ Likewise, it may be that when speaking as experts (and perhaps especially, when delivering bad news to patients ${ }^{21}$ ) it may be that one has a duty to be explicit in one's communication, which includes whenever possible giving more details about what one knows. But this duty is plausibly simply a Gricean one such that one must cancel the conversational implicature that one is able to be as explicit as an expert is expected to be on that occasion. ${ }^{22}$

\section{Conclusion}

In this paper I have defended KNA-S* from a certain style of counterexample. Though I have focused on Lackey's cases here, it is worth noting that the strategy developed to challenge the common intuitions about such cases will arguably extend (mutatis mutandis) to any attempted counterexample to a sufficiency direction of the norm of assertion. ${ }^{23}$ I have not here presented positive arguments that knowledge, even if isolated and second-hand, is sufficient for epistemically permissible assertion. It may turn out that a sufficiency direction of the knowledge norm is implausible for other reasons. My aim has been to argue that relying on cases of isolated second-hand knowledge, in assessing the epistemic propriety

\footnotetext{
${ }^{19}$ Coffman 2011 raises this point.

${ }^{20}$ Indeed, perhaps doctors should only deliver such news in a hedged or indirect manner rather than the direct method of flat-out asserting them, since the latter seems too blunt: much better than 'You have cancer' is 'The test results indicate that you have cancer,' or 'I'm sorry to have to tell you that it appears you have cancer': see Sparks et al. 2007, 185, and 196, Appendix C.

${ }^{21}$ It is worth considering versions of DOCTOR2 where the diagnosis given by Matilda is that Derek does not have cancer; is such an assertion intuitively epistemically impermissible? If not, then perhaps the personal (pragmatic) stakes of the hearer matter to an assertion's epistemic propriety; but I cannot explore this further here.

${ }^{22}$ For discussion of 'one-off Grice' cases of non-explicit messaging, see Fricker 2012 and Hawthorne 2012.

${ }^{23}$ See especially Brown 2008, 555 and 2011, 156-157, and Levin 2008, 374-375.
} 
of an expert's testimony, is problematic for instructive reasons. First, one's intuitions about them depend on several crucial assumptions (and perhaps more assumptions not discussed here) which themselves require clarification and argument. And second, reflecting on such cases reveal subtle issues distinctive of expert testimony on which there is currently no consensus and which deserve further exploration: do we expect of experts that when speaking as experts they are giving their own expert opinion which has been formed by engaging their expertise in a first-hand manner with the relevant evidence or data? (If we do, is that expectation reasonable?) Do we expect that experts always have an obligation to explain to a non-expert what is behind the formation of their opinion? Are there any conditions under which experts may defer to the authority of other experts for a second-hand opinion, or a communal consensus, for the purpose of providing timely efficient testimony to non-experts? Such questions await further investigation. ${ }^{24}$

\section{References}

Benton, Matthew A. 2011. "Two More for the Knowledge Account of Assertion." Analysis 71: 684-687.

—. 2012. "Assertion, Knowledge, and Predictions." Analysis 72: 102105 .

—_. forthcoming. "Gricean Quality.” Noûs .

Blaauw, Martijn. 2012. "Reinforcing the Knowledge Account of Assertion." Analysis 72: 105-108.

Brown, Jessica. 2008. "The Knowledge Norm of Assertion." Philosophical Issues 18: 89-103.

${ }^{24}$ Thanks to Charity Anderson, Lizzie Fricker, Sandy Goldberg, and John Turri for discussion, to two anonymous referees, and especially to Dani Rabinowitz who read and commented on several drafts. This publication was also made possible through the support of a grant from the John Templeton Foundation. The opinions expressed in this publication are those of the author and do not necessarily reflect the views of the John Templeton Foundation. 
- 2010. "Knowledge and Assertion." Philosophy and Phenomenological Research 81: 549-566.

- 2011. "Fallibilism and the Knowledge Norm for Assertion and Practical Reasoning." In Jessica Brown and Herman Cappelen (eds.), Assertion: New Philosophical Essays. Oxford: Oxford University Press.

Carter, J. Adam. 2014. "Engel on Knowledge and Assertion." In A. Meylan J. Dutant, D. Fassio (ed.), Liber Amicorum Pascal Engel, 158-168. University of Geneva.

Carter, J. Adam and Gordon, Emma C. 2011. "Norms of Assertion: The Quantity and Quality of Epistemic Support." Philosophia 39: 615-635.

Coffman, E. J. 2011. "Two Claims about Epistemic Propriety." Synthese 181: $471-488$.

DeRose, Keith. 2009. The Case for Contextualism. Oxford: Clarendon Press.

Douven, Igor. 2006. "Assertion, Knowledge, and Rational Credibility." The Philosophical Review 115: 449-485.

Fantl, Jeremy and McGrath, Matthew. 2009. Knowledge in an Uncertain World. Oxford: Oxford University Press.

Fricker, Elizabeth. 2012. "Stating and Insinuating." Proceedings of the Aristotelian Society, Supplementary Volumes 86: 61-94.

Gerken, Mikkel. 2014. "Same, Same But Different: the Epistemic Norms of Assertion and Practical Reasoning." Philosophical Studies 168: 725-744.

Green, Adam. forthcoming. "Deficient Testimony is Deficient Teamwork." Episteme .

Hawthorne, John. 2004. Knowledge and Lotteries. Oxford: Clarendon Press.

—. 2012. "Some Comments on Fricker's 'Stating and Insinuating'." Proceedings of the Aristotelian Society, Supplementary Volumes 86: 95-108.

Lackey, Jennifer. 2007. "Norms of Assertion.” Noûs 41: 594-626.

- 2008. Learning from Words: Testimony as a Source of Knowledge. Oxford: Oxford University Press. 
—. 2011. "Assertion and Isolated Second-Hand Knowledge." In Jessica Brown and Herman Cappelen (eds.), Assertion: New Philosophical Essays, 251-275. Oxford: Oxford University Press.

—. 2013. "Deficient Testimonial Knowledge." In Tim Henning and David P. Schweikard (eds.), Knowledge, Virtue, and Action: Putting Epistemic Virtues to Work. New York: Routledge.

Levin, Janet. 2008. "Assertion, Practical Reason, and Pragmatic Theories of Knowledge." Philosophy and Phenomenological Research 76: 359-384.

MacFarlane, John. 2011. "What is Assertion?" In Jessica Brown and Herman Cappelen (eds.), Assertion: New Philosophical Essays, 79-96. Oxford: Oxford University Press.

McGrath, Matthew. 2010. "Contextualism and Intellectualism." Philosophical Perspectives 24: 383-405.

McKinnon, Rachel. 2012. "What I Learned in the Lunch Room about Assertion and Practical Reasoning." Logos and Episteme 3: 565-569.

—. 2013. "The Supportive Reasons Norm of Assertion." American Philosophical Quarterly 50: 121-135.

Rescorla, Michael. 2009. "Assertion and Its Constitutive Norms." Philosophy and Phenomenological Research 79: 98-130.

Sosa, Ernest. 2011. Knowing Full Well. Princeton: Princeton University Press.

Sparks, Lisa, Villagran, Melinda M., Parker-Raley, Jessica, and Cunningham, Cory B. 2007. "A Patient-Centered Approach to Breaking Bad News: Communication Guidelines for Health Care Providers." Journal of Applied Communication Research 35: 177-196.

Turri, John. 2010. "Prompting Challenges." Analysis 70: 456-462.

- 2011. "The Express Knowledge Account of Assertion." Australasian Journal of Philosophy 89: 37-45.

—. 2014. "Knowledge and Suberogatory Assertion." Philosophical Studies 167: 557-567. 
Weiner, Matthew. 2005. "Must We Know What We Say?" The Philosophical Review 114: 227-251.

Williamson, Timothy. 2000. Knowledge and its Limits. Oxford: Oxford University Press. 